\title{
The Tibetan Plateau is a natural laboratory for studying organic evolution and environmental change
}

\author{
Zhekun $\mathrm{ZHOU}^{1^{*}}$ \& Tao DENG ${ }^{2,3,4}$ \\ ${ }^{1}$ Key Laboratory of Tropical Forest Ecology, Xishuangbanna Tropical Botanical Garden, Chinese Academy of Sciences, \\ Xishuangbanna 666303, China; \\ ${ }^{2}$ Key Laboratory of Vertebrate Evolution and Human Origins, Institute of Vertebrate Paleontology and Paleoanthropology, \\ Chinese Academy of Sciences, Beijing 100044, China; \\ ${ }^{3}$ CAS Center for Excellence in Life and Paleoenvironment, Beijing 100044, China; \\ ${ }^{4}$ University of Chinese Academy of Sciences, Beijing 100049, China
}

Received September 11, 2019; revised December 10, 2019; accepted December 11, 2019; published online December 27 , 2019

Citation: Zhou Z, Deng T. 2020. The Tibetan Plateau is a natural laboratory for studying organic evolution and environmental change. Science China Earth Sciences, 63: 169-171, https://doi.org/10.1007/s11430-019-9563-x

Today's fauna and flora are a continuation from their geological past. In order to better understand how patterns of biodiversity form and organic evolution takes place, it is necessary to study these flora and fauna over time. Furthermore, modern patterns of biodiversity are a synergistic product of organic evolution and environmental change. Environmental factors both today and in the geological past deeply impact patterns of biodiversity. Thus, paleoenvironments must be reconstructed by studying the compositions of faunal and floral assemblages, and by taking approaches as diverse as leaf physiognomy and the examination of tooth enamel composition.

The formation of the Tibetan Plateau is the most significant geological event of the Cenozoic. The concomitant topographical changes profoundly altered atmospheric circulation as well as biodiversity in both Asia and around the world. Consequently, the Tibetan region can be regarded as a natural laboratory for studying organic evolution and geological environmental change. As several studies have demonstrated, fossils are the key to open this laboratory. One pioneering study used oak fossils (Quercus sect. Heterobalanus) found at $5600 \mathrm{~m}$ on Xixiabangma Mountain (elev. $>8000 \mathrm{~m}$ ) in the Himalayas to reconstruct paleoaltitudes of

* Corresponding author (email: zhouzk@xtbg.ac.cn) the Tibetan Plateau (Xu et al., 1973). More recently, Su et al. (2019) suggested that Tibet has a complex orographic history and that during the Paleogene the core of Tibet did not have a high plateau. They arrived at these conclusions by integrating insights from palm fossil studies, palm ecological niches, and climate modelling. Comprehensive analysis of the Pliocene mammalian fauna of Tibet led Deng et al. (2011) to propose the 'Out of Tibet' hypothesis, which provides new insights into how phylogeny and biogeography can be used to study modern mammals.

Decades of hard work and paleontological research in Tibet have led to great progress and the continued discovery of many important fossils. The geological and biological significance of these fossils has transformed our understanding of the Cenozoic faunal and floral assemblages of Tibet. However, Tibet covers a huge area, and there have been an insufficient number of fossils found in Tibet to fully recognize the composition of the Cenozoic Tibetan biota.

To rectify this limitation, the Strategic Priority Research Program of the Chinese Academy of Sciences and The Second Tibetan Plateau Scientific Expedition and Research Program (STEP) are recovering more and more new fossils. Here, we edit a special topic, named as "Cenozoic mammals and plants from the Tibetan Plateau and their biogeographical significance". This special topic consists of five 
papers covering various aspects of Cenozoic biota from the Tibetan Plateau.

The first paper of this special topic addresses the profound environmental changes in Tibet underwent throughout the Cenozoic, when it was transformed from "a paradise of tropical animals and plants" to "the cradle of the Ice Age mammalian fauna" (Deng et al., 2019). Deng et al. (2019) use recent animal and plant fossils from Tibet to provide a general overview of the changing biodiversity on the Tibetan Plateau and its global influence. They propose that Tibet has served as a junction station in the history of modern biodiversity and it has been (1) a locus where endemism originates; (2) the source of radiations "Out of Tibet"; and (3) a route for intercontinental dispersal.

Li et al. (2019) report a micromammalian fauna from the latest Middle Miocene (about $12.5 \mathrm{Ma}$ ) and a pollen flora discovered from the top of the Shimagou Formation in the Kumkol Basin, northern Tibetan Plateau, Xinjiang. Within this work they establish a new extinct species of ground squirrel. Furthermore, they report that the micromammalian fauna from the Kumkol Basin shares high levels of similarity with contemporary faunas from Europe and northern China. The flora reconstructed by pollen displays a mixture of evergreen broadleaved forest and dry and warm steppe landscape. The ecotypes of the latest Middle Miocene fauna and flora were markedly different from those of modern animals and vegetation in the Kumkol Basin, indicating that the regional climate was more benign in the past.

Ni et al. (2019) have applied a Bayesian tip-dating method to infer the relationships and divergence times of 50 Asian Paleogene mammalian faunas. Based on the results of this analysis, they discuss the correlation between paleogeography and mammalian fauna turnovers. They found that a passage between India and other parts of Asia allowed mammalian dispersal before the Early Paleocene, 64.8-61.3 Ma. At that time, the mammalian faunas between India and other parts of Asia were similar. This exchange occurred at around the earliest postulated collision date between India and Eurasia and suggests land contact as early as the Danian, Early Paleocene. From 57.1 to $47.2 \mathrm{Ma}$, the Indian subcontinent probably had a habitat different from the main part of Asia, as reflected from the composition of these mammalian faunas. The very remote divergence time (64.8 Ma) estimated by Bayesian inference reflects mammalian fauna turnover during the Eocene-Oligocene transition. Until the end of Oligocene, no mammalian exchange took place between the Arabian Peninsula and the Asian mainland, suggesting the presence of strong migration barriers.

Huang et al. (2019) describe a plant fossil assemblage from the Pliocene strata of the Zanda Basin in western Tibet. Twenty-one species belonging to 12 genera and 10 families are recognized. This fossil assemblage shows that the Pliocene vegetation in the Zanda Basin was mostly composed of deciduous shrubs such as Cotoneaster, Spiraea, Caragana, Hippophae, Rhododendron, and Potentilla fruticosa. The leaves of these taxa were generally small. Paleoclimate reconstruction shows that this area had higher temperatures and precipitation in the Pliocene than today, and a distinctly seasonal precipitation regime existed. The paleoelevation of the Zanda Basin in the Pliocene was similar to that of modern times. This research provides insight into central Asian aridification. Specifically, the gradual increase in aridity that began in the late Cenozoic caused not only substantive changes to the flora, but also a transition in the vegetation from tree to shrub to the near desert of recent times.

Zhou and colleagues describe fossil leaves from a new buckthorn species that they have named Berhamniphyllum junrongiae Z. K. Zhou, T. X. Wang et J. Huang from the Upper Eocene strata of the Markam Basin, southeastern Tibet, China. The leaf architecture of this fossil conforms to that of Berhamniphyllum Jones et Dilcher, an extinct Eocene fossil genus reported from America. Additionally, Zhou and colleagues found that distinguishing between Rhamnidium, Berchemia, and Karwinskia cannot be achieved based on leaf characters alone and suggest that these genera should be put in what they call the Berchemia Complex. Berhamniphyllum might represent an extinct common ancestor of the complex. Based on the fossil history of the Complex, they propose that the Berchemia Complex might have originated in the Late Cretaceous in Colombia, South America, and dispersed to North America via Central America during the Eocene. Subsequently, the Complex moved from North America to East Asia via the Bering Land Bridge no later than the Late Eocene. In East Asia, the Berchemia complex first appeared in the Markam Basin on the Qinghai-Tibetan Plateau (Zhou et al., 2019).

All authors in this special topic participated in the Strategic Priority Research Program of the Chinese Academy of Sciences (XDA2007030102, XDA20070203, XDB26000000) and The Second Tibetan Plateau Scientific Expedition and Research Program (STEP). It is impossible for authors to complete their research without support from these programs. Paleontology is a discovery-based discipline and often requires arduous field work. The authors thank their colleagues and students who have assisted in field excavations and documentation.

Although paleontologists have discovered, recorded, interpreted, and reported many Cenozoic mammal and plant fossils from Tibet, the fossil record is still incomplete and is incapable of fully reflecting the complete evolutionary history of the Cenozoic biota of Tibet. Furthermore, the lack of important fossil evidence limits our ability to describe in detail how biota respond to environmental change over time. The papers collected in this special topic offer a glimpse into the history of the region and demonstrate the potential of further exploration and study. 


\section{References}

Deng T, Wang X M, Fortelius M, Li Q, Wang Y, Tseng Z J, Takeuchi G T, Saylor J E, Säilä L K, Xie G P. 2011. Out of Tibet: Pliocene woolly rhino suggests high-plateau origin of Ice Age megaherbivores. Science, 333: $1285-1288$

Deng T, Wu F, Zhou Z, Su T. 2020. Tibetan Plateau: An evolutionary junction for the history of modern biodiversity. Sci China Earth Sci, 63: $172-187$

Huang J, Su T, Li S, Wu F, Deng T, Zhou Z. 2020. Pliocene flora and paleoenvironment of Zanda Basin, Tibet, China. Sci China Earth Sci, 63: 212-223

Li Q, Zhou X, Ni X, Fu B, Deng T. 2020. Latest Middle Miocene fauna and flora from Kumkol Basin of northern Qinghai-Xizang Plateau and pa- leoenvironment. Sci China Earth Sci, 63: 188-201

Ni X, Li Q, Zhang C, Samiullah K, Zhang L, Yang Y, Cao W. 2020. Paleogene mammalian fauna exchanges and the paleogeographic pattern in Asia. Sci China Earth Sci, 63: 202-211

Su T, Spicer R A, Li S H, Xu H, Huang J, Sherlock S, Huang Y J, Li S F, Wang L, Jia L B, Deng W Y D, Liu J, Deng C L, Zhang S T, Valdes P J, Zhou Z K. 2019. Uplift, climate and biotic changes at the EoceneOligocene transition in south-eastern Tibet. Natl Sci Rev, 6: 495-504

Xu R, Tao J R, Sun X J. 1973. On the discovery of a Quercus Semicarpifolia bed in Mount Shisha Pangma and its significance in botany and geology (in Chinese). Acta Bot Sin, 15: 103-119

Zhou Z, Wang T, Huang J, Liu J, Deng W, Li S, Deng C, Su T. 2020. Fossil leaves of Berhamniphyllum (Rhamnaceae) from Markam, Tibet and their biogeographic implications. Sci China Earth Sci, 63: 224-234 